\title{
Ethical Challenges Faced by Students in the Educational Environment of Artificial Intelligence
}

\author{
Zhonghua Wang \\ Central China Normal University \\ CCNU \\ Wuhan, Hubei
}

\author{
Jing Zhai* \\ Central China Normal University \\ CCNU \\ Wuhan, Hubei
}

\begin{abstract}
With the development of new generation information technology, human society is entering the era of artificial intelligence, and the application of artificial intelligence has gradually entered the field of education. As the main body of teaching, information technology is applied to education to bring convenience to students' learning and promote students' learning on one hand. On the other hand, it also has some ethical problems that hinder the development of students. Firstly, this work discussed the ethical issues in the application of artificial intelligence in education, and then analyzed the ethical crisis phenomenon generated by artificial intelligence from different aspects; finally, put forward some suggestions for the development of artificial intelligence education applications. Artificial intelligence builders should strengthen the protection of personal data to ensure the privacy of users; students should consciously improve their core literacy, scientific literacy, and humanistic literacy, improve their abilities, and then better enjoy the artificial intelligence.
\end{abstract}

Keywords-artificial intelligence; ethics; students; information technology

\section{ARTIFICIAL INTELLIGENCE AND ITS DEVELOPMENT}

Artificial Intelligence (AI) is a new technical science that studies and develops theories, methods, techniques, and applications system of simulating, extending, and extending human intelligence. Research in this area includes robotics, language recognition, image recognition, natural language processing, and expert systems. It can be traced back to the ancient Greek period, the study of the laws of human thinking by ancient philosophers and educators laid the theoretical foundation for the development of artificial intelligence. In modern times, mathematicians and scientists in Western countries have driven the rapid development of mathematics, which also laid the foundation of algorithmic ideas for artificial intelligence. At present, many countries have incorporated artificial intelligence into national development strategies, which shows the importance of artificial intelligence. But technology is a double-edged sword, and it must be treated correctly.

\section{The EdUCATIONAL ApPliCATION OF ARTIFICIAL INTELLIGENCE IN CHINA HAS RECEIVED UNPRECEDENTED} ATTENTION

The changes brought about by information technology affect all aspects of society, including education. Every change in technology will bring new changes to the field of education[1]. The rise of the three waves of artificial intelligence has also affected the field of education, and educational technology has ushered in new developments. In recent years, China has issued a series of important documents related to the application of artificial intelligence education. For example, in April 2018, the Ministry of Education issued the "Education Informatization 2.0 Action Plan", proposed "Based on emerging technologies such as Artificial Intelligence, Big Data, and Internet of Things, and relied on various types of smart devices and networks. We will actively carry out research and demonstration of smart education innovation, and promote model reform and ecological reconstruction of education supported by new technologies." In November 2018, the 5th "Future Education in the Big Data Era" Forum released the "Artificial Intelligence + Education" Blue Book.[2]. All of these indicate that China attaches great importance to the development of artificial intelligence's application in education, and China's education has entered the era of artificial intelligence.

\section{EdUCATIONAL ETHICS Plays AN IMPORTANT ROLE IN STUDENT DEVELOPMENT UNDER THE EDUCATIONAL}

\section{APPLICATION ENVIRONMENT OF ARTIFICIAL INTELLIGENCE}

Ethics, the moral code that people should follow when they get along with others [3]. Educational ethics also refers to the relationship between people, people and nature in education, and the rules for dealing with these relationships. The ethics of education is mainly reflected in the students, how do students get along with teachers and companions, and how students can correctly use various new learning devices. The correct ethics plays an important role in shaping students' healthy personality and promotes the continuous improvement of students' personality. [4].

In the context of artificial intelligence education applications, machines are becoming more and more intelligent. Although they cannot surpass humans, their impact are still not to be underestimated. Therefore, in this case, the ethical education of students is particularly important. Students should always keep a clear head and enjoy the convenience brought by artificial intelligence, so that artificial intelligence can really promote the growth and learning of students. 


\section{The Main ETHICAL Issues FaCED By STUdents IN THE} EDUCATIONAL ENVIRONMENT OF ARTIFICIAL INTELLIGENCE

\section{A. Impeding the Development of Students' Key Competency in the Information Age}

1) Improper use of Technical Tools Hinders Students from Thinking, Inventing, and Creating

With the advent of the artificial intelligence era, students learning is not just from books and teachers. At present, the convenience of using the network and the richness of resources make students more willing to use the Internet for the class or after-school learning. Network information resources also enrich the spiritual world of students to a certain extent. However, for students who are not yet fully mature, if they are unable to use the technical tools correctly and are addicted to artificial intelligence and the virtual environment it creates, all the things are handled by the robot, that is, the "anesthetic problem" of the virtual environment will occur.

Practical applications of artificial intelligence include expert systems, intelligent search, theorem proving, knowledge acquisition, and so on. Baidu in China also involves artificial intelligence. In 2016, the "Baidu Brain" project was officially launched, dedicated to building a comprehensive artificial intelligence platform, which further improved the user's sense of use, but also brought a certain negative impact. For example, the intelligent search function makes students rely on "Baidu" and "Google" at once, whenever students encounter problems in learning, that is, "net search" phenomenon. Even some of the students directly copied the answers from Baidu and Google's search on the paper, that is, the "net copy" group. Due to the excessive dependence of students on artificial intelligence, many things must be assisted by machine assistance, which makes the students' memory, thinking ability and inventiveness greatly weakened, and hinders the development of students to a large extent. Thinking, invention, and creation are the essential characteristics and unique development advantages that distinguish people from other things. If the technical equipment in the artificial intelligence environment is not used correctly, human beings will gradually lose their unique advantages, which may lead to the arrival of the era of machine control.

\section{2) Intelligent Push Puts Higher Demands on Student} Information Literacy

In the era of artificial intelligence, information is filled in every corner of society. The development of technology enables smart devices to intelligently push by analyzing massive amounts of data and understanding user preferences. However, the machine may not accurately push the absolutely correct information to the user, which may result in the student absorbing the wrong information due to immature judgment, or push the wrong information due to technical errors such as code. This is a great obstruction for the healthy growth of students. The ability to collect and judge information determines the horizons of students, and is the core of their grasp of the latest research results [5]. This requires students to improve information literacy, that is, the ability to identify information and process information, which is the ability that students must have in the information age. Students should improve their sensitivity to information, improve their ability to identify and process information, and avoid being overwhelmed in massive amounts of information.

\section{B. Emotional Problems of Human Beings in the Machine Age}

In the era of artificial intelligence, although machines are more "intelligent," teachers will not be replaced by machines because machines can never replace the emotional impact of teachers on students. In addition, human beings must learn to deal with the relationship between people and the relationship between humans and robots.

\section{1) Alienation of Family and Friendship}

Students, especially the lower grades, are in an emotionally sensitive period, and relationships with parents are often evasive. They are more willing to stay alone and not willing to communicate with others. The rapid development of smart devices may cause students to be immersed in the virtual environment created by artificial intelligence, which will eventually lead to a weaker relationship with family members and friends in the real environment. Because of the lack of communication, others are unable to know the problems of students, unable to solve problems in time, this may cause depression, autism and other issues, which is not conducive to the healthy growth of students' psychology. In recent years, more and more teenagers are addicted to mobile phones. Adolescents whose self-control is not yet fully mature, indulging in mobile phones often lead them to deviate from the real world, alienate relatives and friends, and even require the treatment of psychologists.

\section{2) The disintegration of School, Teacher Trust and}

\section{Authority}

In the era of Educational Informatization, teaching is no longer dominated by teachers in classrooms, and knowledge is less subject to textbooks. Nowadays, students can collect information and learn knowledge through online inquiries, and the learning environment is becoming more and more open. Students can listen to the opinions of authoritative experts without leaving home, and they can also communicate online and solve problems in time. Therefore, the absolute authority of schools and teachers in the minds of students has collapsed to a certain extent. Teachers are no longer the authority, and schools are no longer the only environment on which students depend. Artificial intelligence disintegrates the trust and authority of traditional teaching places and teaching implementers in students' minds to varying degrees. Ashok Goel, a professor of computer science at the Georgia Institute of Technology in the United States, created an artificial intelligence assistant to handle the daily standard answer. The robot was named Jill Watson. Jill started to be used in the spring class in 2016, and the students asked Gil more for help than teachers when they encountered problems. This enhanced the students' trust and admiration for artificial intelligence robots, and thus more liked and accepted the learning experience that robots brought to them. The subtle influence has weakened the trust and authority of teachers in the hearts of students. 


\section{3) Mental Damage, Lack of Emotional Experience}

In the era of artificial intelligence, in order to more accurately understand the students' learning status, obtain the learning rules, and improve the learning effect, some scholars try to use wearable devices to collect data. Through data analysis, they can more accurately understand the state of the cerebral cortex, such as students' attention. When students are in class, the researchers let them wear "helmets", install monitoring terminal equipment, and monitor the students' every move, which will make students feel monitored and have no sense of freedom. It will cause students' tiredness of learning, fear of learning, and even refusal to learn, which not only hinders the normal learning of students but also brings certain harm to the growth of students' minds. At the same time, using intelligent robots to learn the experience, what students get is only the knowledge itself, but did not bring a certain emotional experience, and ultimately lead to “indifferent world." Therefore, artificial intelligence can't completely replace the role of teachers as student emotional communicators, and the teacher's role in cultivating students' spiritual world is irreplaceable [6].

\section{SOME SUGGESTIONS IN THE EDUCATIONAL APPLICATION OF ARTIFICIAL INTELLIGENCE}

\section{A. Suggestions for the construction of artificial intelligence}

From a technical perspective, the development of artificial intelligence has matured, and the focus should be on the security of user's information. On the one hand, it is necessary to educate developers on ethics and morals to ensure that developers do not sell personal information for personal interests; On the other hand, we must strengthen technical protection to prevent leakage of user's privacy data due to technical errors [7].

\section{B. Advice for students' own development}

1) Grasping the essence of key Competency - self-learning ability

In today's information age, the growth of new things is very rapid, which requires us to improve our key competency in this era. As the essence and core of key competency, selflearning ability needs to be possessed by every student. For a large amount of information, we must have a self-learning plan that suits ourselves. We must be able to acquire effective knowledge accurately and quickly, consciously upgrade ourselves, and actively increase our knowledge reserves. We must not be dominated by a large amount of information.

2) The key to cultivating science and technology literacy innovation and creativity

In the future society, there is no shortage of people who can learn knowledge, what is missing is someone with innovative ability. Innovative ability is the key to scientific literacy, and every student in the future society must be equipped to better promote the advancement of technology. In a smart society, the core of learning is to cultivate students' innovative ability, which is a skill that cannot be replaced by machines. Therefore, we must make full use of machinery and equipment to cultivate our own innovation and creativity.

3) Acquire the core of humanistic literacy - emotional processing ability

No matter what era, the emotional communication between people is indispensable. Although learning is the nature of students, interaction with others is also an indispensable part of the healthy growth of students. Therefore, emotional processing ability is also a skill that students must pay attention to. This skill is not owned by the machine, and it is also impossible for the machine to provide for students. Students should consciously improve their emotional processing skills in the process of getting along with their family, teachers and peers, and learn from the best people.

\section{SUMMARY}

With the rapid development of artificial intelligence, the application of artificial intelligence education has gradually deepened. As the main body of learning, students' learning has also undergone earth-shaking changes. On the one hand, artificial intelligence effectively promotes students' learning and improves students' academic performance. On the other hand, it also brings some ethical issues that cannot be ignored. We must foster strengths and circumvent weaknesses, and avoid the phenomenon of counter-ethics while enjoying the scientific and technological achievements so that science and technology can serve humanity better. At the same time, we must also pay attention to strengthening the supervision of artificial intelligence technology, so that artificial intelligence can serve human beings while avoiding information leakage and other ethical violations.

\section{REFERENCES}

[1] $\mathrm{Xu}$ Ye and Huang Yao, "Wisdom Education: A New Ecology of Artificial Intelligence Education”, Social Sciences in Ningxia, Ningxia, vol. 3, pp. 139-145, 2019. (In Chinese)

[2] Liang Na and Jiang Yuantao, "The Role Reconstruction of Primary and Secondary School Teachers in the Age of Artificial Intelligence", Teaching Monthly Primary School Edition (comprehensive), Zhejiang, vol. 5, pp. 12-15, 2019. (In Chinese)

[3] Chen Guoqiang, Concise Cultural Anthropology Dictionary. Hangzhou: Zhejiang People Publishing House Press. (In Chinese)

[4] Wang Kai and Zhou Yanyan, "The Importance of Chinese Traditiona Ethics to the Importance of College Students' Growth”, Office Operations, Beijing, vol. 8, pp. 53-54, 2019. (In Chinese)

[5] Hou Haoxiang "The Dilemma and Turn of Cultivating Innovative Talents in Colleges and Universities in the Intelligent Age", China Educational Technology, Beijing, vol. 6, pp. 21-28, 2019. (In Chinese)

[6] Song Lingqing and Xu Lin, "The Logical Starting Point and Boundary of Artificial Intelligence in Education Application-Taking Knowledge Learning as an Example”, China Educational Technology, Beijing, vol. 6, pp. 14-20, 2019.

[7] Gao Tingting and Guo Jiong, "Research Review on the Application of Artificial Intelligence in Education”, Modern Educational Technology, Beijng, vol.1, pp.11-17, 2019. (In Chinese) 